Journal of Antimicrobial Chemotherapy (1983) 12, Suppl. D, 141-148

\title{
Comparative study of imipenem in severe infections
}

\author{
J. D. Baumgartner and M. P. Glauser \\ Division des Maladies Infectieuses, Département de Médecine, \\ Centre Hospitalier Universitaire Vaudois, 1011 Lausanne, Switzerland
}

\begin{abstract}
Forty patients with severe bacterial infections due to micro-organisms known or presumed to be sensitive to both study antibiotics, were randomized to receive either imipenem with cilastatin, $500 \mathrm{mg} / 500 \mathrm{mg}$ iv tid (20 patients), or cefotaxime, $2 \mathrm{~g}$ iv tid (20 patients). The types of infections observed were equally distributed between the 2 groups, and consisted of 18 complicated urinary tract infections, 9 pneumonia, 7 bone and soft tissue infections, 4 septicaemia of unknown origin and 2 intravenous-catheter-related septicaemia. In the imipenem group, 12 patients were bacteraemic, compared to 10 in the cefotaxime group. The micro-organisms observed were evenly distributed with Escherichia coli (22 cases) and Klebsiella pneumoniae ( 6 cases) being the most frequent. Sixteen patients were cured in the imipenem group and 15 in the cefotaxime group, while 2 and 2 improved, 2 and 1 relapsed and 0 and 2 did not respond to the therapy, respectively. In the imipenem group, no clinical side effects were observed while 5 patients had mild reactions in the cefotaxime group ( 2 fever, 1 skin rash, 1 oral candidiasis and 1 diarrhoea). Imipenem thus appeared as effective and well tolerated as cefotaxime in the treatment of severely infected patients.
\end{abstract}

\section{Introdaction}

The introduction of a new antibiotic such as imipenem is almost always accompanied by a detailed body of research information on its pharmacology (Follath et al., 1981; Kropp et al., 1982), in-vitro activity (Kesado, Hashizume \& Asahi, 1980; Livermore, Williams \& Williams, 1981; Livingston, Elliott \& Cobbs, 1981; Cohn, Reiner \& Reller, 1982; Kesado et al., 1982; Witte, Sapico \& Canawati, 1982), performance in animal studies (Kropp et al., 1980; Patamasucon \& McCracken, 1982; Pennington \& Johnson, 1982; Baumgartner \& Glauser, 1983) and efficacy and tolerance in early clinical trials (Calandra, Ricci \& Brown, 1983; Tally, Ho \& Gorbach, 1983) with relatively straightforward, if somewhat therapeutically unchallenging, clinical material. We were, therefore, all the more interested in the outcome of a study we recently completed, in which we had the opportunity to gain experience with imipenem in a group of severely ill patients, at a relatively early stage of the compound's research programme. The results of this study, in which the new agent, administered together with its inhibitor of renal tubular metabolism cilastatin, was compared with the established cephalosporin cefotaxime, are presented in this paper. 


\section{Study design and patient popalation}

Our protocol permitted the treatment of a wide range of proven or suspected bacterial infections in hospitalized patients of both sexes, between the ages of 18 and 75 years. Having made certain that potential patients met all exclusion criteria, which included terminal illness, known or presumed hypersensitivity, established or suspected resistance of the infecting organism, severe cardiac, renal or hepatic illness, and pregnancy and lactation, treatment was randomized to imipenem/cilastatin $500 \mathrm{mg} / 500 \mathrm{mg}$ intravenously every $8 \mathrm{~h}$, or cefotaxime $2 \mathrm{~g}$ intravenously every $8 \mathrm{~h}$. Therapy was maintained for a minimum of 5 , and a maximum of 18 days.

All patients received a full physical examination at the start of the study, and were reviewed daily during therapy. In the acute phase, vital signs were recorded at least four-hourly, and at least daily during the convalescent period. Paired aerobic and anaerobic blood cultures, together with cultures and Gram stains from all known or suspected sites of infection, were obtained for each patient before therapy. Standard antibiotic disc susceptibility tests, including the two test antibiotics, were part of the routine pre-study investigations. Follow-up cultures from all sources were obtained throughout the treatment period in accordance with the clinical course, but included routine cultures from the primary site $48 \mathrm{~h}$ after the start of therapy and, for urinary infections, at 1 week, and again at 6 weeks, following cessation of treatment.

In the assessment of treatment efficacy, the following definitions were used:

Cure Disappearance of clinical evidence of infection. Sterile cultures obtained during, and 1 to 3 days after, therapy (and at the late follow-up for urinary tract infections).

Improvement Marked reduction in clinical symptoms and bacteriological growth, without complete disappearance within 14 days.

Relapse Cure during treatment; reappearance (with or without symptoms) of the causative organism after conclusion of therapy.

Failure Absence of response to therapy.

\section{Results}

A total of $\mathbf{4 0}$ patients was studied, 20 in each treatment group. Table I details some of the characteristics of this randomized population, which appears to be well balanced for the parameters recorded. In all cases the degree of the infection was judged to be severe. In addition, as shown in Table II the group presented challenging diagnostic and management decisions, as the majority of patients had significant underlying pathology.

The types of infections observed during the study period were evenly distributed between the two treatment groups; with pyelonephritis, pneumonia, and bone and soft tissue infections accounting for $85 \%$ of the total diagnoses. Tables III and IV present an analysis of these data by organisms cultured, their presence in blood and therapeutic outcome, for imipenem and cefotaxime, respectively. In the imipenem group, $60 \%$ of the patients had positive blood cultures, compared with $50 \%$ of those in the cefotaxime group. The overall cure rate for imipenem was $80 \%$, and for cefotaxime $75 \%$. Two patients in the cefotaxime group, however, were regarded as therapeutic failures, whereas no patients were so classified in the imipenem group. The cefotaxime-treated infections showed only improvement in two cases, and one patient 
Table I. Patient characteristics

\begin{tabular}{lcc}
\hline & Imipenem & Cefotaxime \\
\hline Patient number & 20 & 20 \\
Mean age (years \pm s.D.) & $51 \cdot 4 \pm 16.0$ & $54 \cdot 8 \pm 17 \cdot 2$ \\
Sex male & 9 & 12 \\
female & 11 & 8 \\
Mean duration of test therapy (days \pm s.D.) & $11.8 \pm 3.5$ & $11 \cdot 5 \pm 2.9$ \\
therapy with & & 2 \\
- amoxycillin & 3 & - \\
-penicillin + chloramphenicol & 3 & 1 \\
- penicillin & 1 & 2 \\
- doxycycline & 1 & 1 \\
\hline
\end{tabular}

had a relapse. The imipenem group had two improvements and two relapses. There thus appeared to be no major differences in therapeutic efficacy between the two antibiotics.

Particular attention was directed to recording the development of new resistant organisms during therapy. Table $V$ gives the results for imipenem and cefotaxime. These data refer only to cases of asymptomatic microbiological colonization. Urinary enterococci and Candida sp. were the most frequently identified resistant organisms in both treatment groups. Pseudomonas aeruginosa resistant to imipenem was found in the sputum of two patients receiving this antibiotic. In one case, there was evidence that the Pseudomonas was sensitive to this antibiotic before the study start. One patient showed symptomatic clinical infection as a result of the emergence of a resistant pathogen during therapy. This was a 72-year-old man with prostatic adenoma

Tabłe II. Frequency of significant underlying disorders

\begin{tabular}{|c|c|c|}
\hline \multirow[b]{2}{*}{ Condition } & \multicolumn{2}{|c|}{$\begin{array}{l}\text { Number of occurrences } \\
\text { in treatment groups }\end{array}$} \\
\hline & Imipenem & Cefotaxime \\
\hline \multicolumn{3}{|l|}{ Cardiovascular disease (cardiac and arterial } \\
\hline Neurological disease (multiple sclerosis, & 3 & 4 \\
\hline epilepsy, hemiplegia) & 4 & 1 \\
\hline Cirrhosis (viral, alcoholic) & 1 & 3 \\
\hline Connective tissue disorder & 0 & 3 \\
\hline Diabetes mellitus & 3 & 3 \\
\hline Chronic obstructive lung disease & 0 & 2 \\
\hline Severe trauma & 3 & 0 \\
\hline Surgery within 14 days preceding study & 4 & 1 \\
\hline Cancer local & 1 & 1 \\
\hline with metastases & 1 & 0 \\
\hline chronic haematological & 1 & 1 \\
\hline
\end{tabular}

- Some patients had more than one underlying condition. Five patients in the cefotaxime group, and four in the imipenem, had no underlying disorders. 
Table III. Nature of infections treated and therapeutic outcome-imipenem

\begin{tabular}{|c|c|c|c|c|c|c|c|}
\hline \multirow{2}{*}{$\begin{array}{l}\text { Type of } \\
\text { infection }\end{array}$} & \multirow[b]{2}{*}{ Organism } & \multirow{2}{*}{$\begin{array}{c}\text { No. of } \\
\text { organisms }\end{array}$} & \multirow{2}{*}{$\begin{array}{l}\text { No. of positive } \\
\text { blood cultures }\end{array}$} & \multicolumn{4}{|c|}{ No. of patients } \\
\hline & & & & Cured & Improved & Relapsed & Failure \\
\hline \multirow{3}{*}{$\begin{array}{l}\text { Complicated } \\
\text { urinary tract } \\
\text { infection } \\
(9 \text { patients })^{*}\end{array}$} & E. coli & 7 & 5 & 6 & - & 1 & - \\
\hline & $\begin{array}{l}\text { E. coli + Serratia } \\
K \text {. pneumoniae }+ \\
E . \text { coli + Proteus }\end{array}$ & 1 & 1 & 1 & - & - & - \\
\hline & vulgaris & 1 & 1 & - & 1 & 一 & - \\
\hline \multirow{2}{*}{$\begin{array}{l}\text { Pneumonia } \\
\text { (4 patients) }\end{array}$} & K. pneumoniae & 1 & - & 1 & - & - & - \\
\hline & Unknown & 3 & - & 2 & 1 & - & - \\
\hline \multirow{4}{*}{$\begin{array}{l}\text { Bone and soft } \\
\text { tissue } \\
\text { (4 patients) }\end{array}$} & $E$. coli & 1 & 1 & - & - & 1 & - \\
\hline & Strep. pyogenes & 1 & - & 1 & - & 一 & - \\
\hline & Strep. pneumoniae & 1 & 1 & 1 & - & - & - \\
\hline & Group G streptococcus & 1 & - & 1 & - & - & - \\
\hline \multirow{3}{*}{$\begin{array}{l}\text { Septicaemia of } \\
\text { unknown origin } \\
\text { ( } 2 \text { patients) } \\
\text { iv catheter } \\
\text { ( } 1 \text { patient) }\end{array}$} & Meningococcus group B & 1 & 1 & 1 & - & - & - \\
\hline & K. pneumoniae & 1 & 1 & 1 & - & - & - \\
\hline & K. pneumoniae & 1 & 1 & 1 & - & 一 & 一 \\
\hline
\end{tabular}

- Includes five cases for whom oral antibiotic therapy was continued for 4 weeks after the study period. 
Table IV. Nature of infections treated and therapeutic outcome-cefotaxime

\begin{tabular}{|c|c|c|c|c|c|c|c|}
\hline \multirow{2}{*}{$\begin{array}{l}\text { Type of } \\
\text { infection }\end{array}$} & \multirow[b]{2}{*}{ Organism } & \multirow{2}{*}{$\begin{array}{c}\text { No. of } \\
\text { organisms }\end{array}$} & \multirow{2}{*}{$\begin{array}{l}\text { No. of positive } \\
\text { blood cultures }\end{array}$} & \multicolumn{4}{|c|}{ No. of patients } \\
\hline & & & & Cured & Improved & Relapsed & Failure \\
\hline \multirow{2}{*}{$\begin{array}{l}\text { Complicated } \\
\text { urinary tract } \\
\text { infection } \\
\text { (9 patients)* }\end{array}$} & E. coli & 8 & 5 & 6 & 1 & 1 & - \\
\hline & $K$. pneumoniae & 1 & 1 & 1 & 一 & 一 & - \\
\hline \multirow{3}{*}{$\begin{array}{l}\text { Pneumonia } \\
\text { (5 patients) }\end{array}$} & E. coli & 1 & 1 & 一 & - & - & 1 \\
\hline & Mixed anaerobic flora & 1 & - & - & - & - & 1 \\
\hline & Unknown & 3 & - & 3 & - & - & - \\
\hline \multirow{4}{*}{$\begin{array}{l}\text { Bone and soft } \\
\text { tissue } \\
\text { ( } 3 \text { patients) }\end{array}$} & E. coli + & & & & & & \\
\hline & $\begin{array}{l}\text { Acinetobacter } \\
\text { Staph. aureus + }\end{array}$ & 1 & - & 1 & 一 & 一 & - \\
\hline & Strep. pyogenes & 1 & - & 1 & - & - & - \\
\hline & Staph. aureus & 1 & - & - & 1 & - & - \\
\hline $\begin{array}{l}\text { Septicaemia of } \\
\text { unknown origin } \\
\text { ( } 2 \text { patients) }\end{array}$ & E. coli & 2 & 2 & 2 & - & - & - \\
\hline $\begin{array}{l}\text { iv catheter } \\
\text { (1 patient) }\end{array}$ & $K$. pneumoniae & 1 & 1 & 1 & - & - & - \\
\hline
\end{tabular}

- Includes three cases for whom oral antibiotic therapy was continued for 4 weeks after the study period. 
Table V. Development of resistant strains (colonization)

\begin{tabular}{|c|c|c|c|}
\hline \multirow[b]{2}{*}{ Source } & \multirow[b]{2}{*}{ Organism } & \multicolumn{2}{|c|}{$\begin{array}{l}\text { No. of resistant organisms } \\
\text { in patients receiving }\end{array}$} \\
\hline & & imipenem & cefotaxime \\
\hline \multirow{4}{*}{ Urine } & Enterococeus & 2 & 2 \\
\hline & Candida spp. & 3 & 4 \\
\hline & Staph. epidermidis & - & 1 \\
\hline & Acinetobacter sp. & 一 & 1 \\
\hline Wound & Enterococcus & - & 1 \\
\hline Sputum & Candida spp. & 1 & 1 \\
\hline sputun & Ps. aeruginosa & $2^{*}$ & 一 \\
\hline
\end{tabular}

- Present pre-study.

and bladder diverticulum who received cefotaxime for an Escherichia coli pyelonephritis following bladder catheterization. The organism and the patient's symptoms initially disappeared; but a symptomatic cefotaxime-resistant enterococcal cystitis supervened. This was treated successfully with a course of nitrofurantoin.

Tolerance of the test drugs was assessed by the frequency of clinical side effects, and deviations from the normal ranges of a battery of haematological and biochemical tests performed before, during and after the study. None of the 20 patients who received imipenem had a drug-related clinical adverse reaction. Five of the 20 cefotaxime-treated patients had side effects including diarrhoea (one case), fever (two cases), skin rash (one case) and oral candidiasis (one case).

Laboratory screening produced the following results. In the cefotaxime group, two patients developed mild elevations of alkaline phosphatase, and one patient a positive Coombs' test, with no evidence of anaemia. In the imipenem group, there were four mild alkaline phosphatase elevations and three weakly-positive asymptomatic Coombs' tests. Five patients in the imipenem group were noted to have thrombocytosis. Three cases were only moderate elevations, whereas two reached maximum values of $1050 \times 10^{9} / 1$ and $1098 \times 10^{9} / 1$, respectively (upper limit of normal, $\left.350 \times 10^{9} / 1\right)$. These two cases received anti-aggregation therapy. The thrombocytoses were regarded as possibly (four cases) or probably (one case) drug-related. In no case was it considered necessary to alter or discontinue antibiotic therapy.

Although numerous medications were administered together with the test antibiotics during the study, no suggestion of significant interactions was obtained from the clinical or laboratory findings.

\section{Discussion}

All comparative antibiotic studies of this nature suffer to some extent from the protocol exclusion of infections caused by organisms known or presumed to be resistant to either drug. Thus, we were unable to include mixed flora intra-abdominal infections; an indication for which the new antibiotic imipenem could be expected to show interesting results. Within the limitations of the study design, however, we have been able to demonstrate that the new compound compares well for therapeutic efficacy with that of an established cephalosporin. It proved able to cure severe 
infections, such as complicated urinary-tract infections, pneumonia, bone and soft tissue infections and septicaemia. More than half of these cases were bacteraemic.

There were no therapeutic failures in the imipenem group, and two cases were judged as only improved (Table III), a patient with a paravesical abscess and a patient with a pneumonia of unknown origin. There were two cases of relapse: a patient with an $E$. coli vertebral osteomyelitis with bacteraemia, and a man with complicated pyelonephritis.

In the cefotaxime group, 2 therapeutic failures were recorded (Table IV). Therapy was stopped after 3 days in a 48 -year-old chronic alcoholic patient with pulmonary abscess, who developed a severe cellulitis of the foot, from which a cefotaximeresistant mixed anaerobic population was cultured. A second patient with severe chronic lymphatic leukaemia and $E$. coli bacteraemia died on the eleventh day of therapy after a transient improvement. There was one case of asymptomatic relapse with cefotaxime, in a patient with acute complicated pyelonephritis.

Recently, there has been concern regarding the question of bacterial, especially enterococcal, and fungal superinfection during therapy with the newer cephalosporins (Yu, 1981). In our study, resistant strains of enterococci emerged in two patients in the imipenem group, and in three in the cefotaxime group. One patient developed symptomatic enterococcal lower urinary tract superinfection in this latter group. Colonization with Candida albicans occurred in four patients receiving imipenem, and in five receiving cefotaxime. Two patients were colonized with imipenem-resistant Pseudomonas aeruginosa at the end of imipenem treatment.

Imipenem was not associated with drug-related clinical side effects in any of the patients studied. The five cases of thrombocytosis in the imipenem group remain difficult to assess. Thrombocytosis is certainly often a feature following severe infections. Previous studies have apparently not uncovered any increased incidence of this condition, and it would be difficult to postulate a possible mechanism. Cases of local irritation at the infusion site occurred with similar frequency in both treatment groups, and none were regarded as drug-related side effects.

In conclusion, we have shown that, in a group of severely infected patients, many of whom had significant concomitant pathology, the new carbapenem antibiotic imipenem was as effective therapeutically as the established cphalosporin cefotaxime. No drug-related clinical side-effects occurred in any of the patients treated with the new agent. It should, therefore, find a useful place in the therapy of a wide range of infections in hospitalized patients.

\section{References}

Baumgartner, J. D. \& Glauser, M. P. (1983). Comparative imipenem treatment of Staphylococcus aureus endocarditis in the rat. Journal of Antimicrobial Chemotherapy 12 , Suppl. D, 79-87.

Calandra, G. B., Ricci, F. M. \& Brown, K. R. (1983). Comparison of the safety and tolerability of N.F. thienamycin (MK 0787)/MK 0791 to cefazolin. Proceedings of the 13th International Congress of Chemotherapy (Spitzy, K. H. \& Karrer, K., Eds), Vienna, Part 95/69-73.

Cohn, D. L., Reimer, L. G. \& Reller, L. B. (1982). Comparative in-vitro activity of MK 0787 ( $N$ formimidoyl thienamycin) against 540 blood cultures isolates. Journal of Antimicrobial Chemotherapy 9, 183-94.

Follath, F., Geddes, A. M., Spring, P. et al. (1981). Tolerability and pharmacokinetics of single doses of $N$-formimidnyl thienamycin. 2Ist Interscience Conference on Antimicrobial Agents and Chemotherapy, Chicago. Abstract 590. 
Kesado, T., Hashizume, T. \& Asahi, Y. (1980). Antibacterial activities of a new stabilized thienamycin, $N$-formimidoyl thienamycin, in comparison with other antibiotics. Antimicrobial Agents and Chemotherapy 17, 912-7.

Kesado, T., Watanabe, K., Asahi, Y., Isono, M. \& Ueno, K. (1982). Susceptibilities of anaerobic bacteria to $N$-formimidoyl thienamycin (MK 0787) and to other antibiotics. Antimicrobial Agents and Chemotherapy 21, 1016-22.

Kropp, H., Sundelof, J. G., Kahan, J. S. \& Birnbaum, J. (1980). MK 0787 ( $N$-formimidoyl thienamycin): evaluation of in vitro and in vivo activities. Antimicrobial Agents and Chemotherapy 17, 993-1000.

Kropp, H., Sundelof, J. G., Hajdu, R. \& Kahan, F. M. (1982). Metabolism of thienamycin and related carbapenem antibiotics by the renal dipeptidase, dehydropeptidase-I. Antimicrobial Agents and Chemotherapy 22, 62-70.

Livermore, D. M., Williams, R. J. \& Williams, J. D. (1981). In vitro activity of MK 0787 ( $N$ formimidoyl thienamycin) against Pseudomonas aeruginosa and other Gram-negative organisms and its stability to their beta-lactamases. Journal of Antimicrobial Chemotherapy 8, 355-62.

Livingston, W. K., Elliott, A. M. \& Cobbs, C. G. (1981). In vitro activity of $N$-formimidoyl thienamycin (MK 0787) against resistant strains of Pseudomonas aeruginosa, Staphylococcus epidermidis, Serratia marcescens and Enterococcus spp. Antimicrobial Agents and Chemotherapy 19, 114-6.

Patamasucon, P. \& McCracken, G. H., Jr. (1982). Pharmacokinetics and bacteriological efficacy of $\mathrm{N}$-formimidoyl thienamycin in experimental $E$. coli meningitis. Antimicrobial Agents and Chemotherapy 21, 390-2.

Pennington, J. E. \& Johnson, C. E. (1982). Comparative activities of $N$-formimidoyl thienamycin, ticarcillin and tobramycin against experimental Pseudomonas aeruginosa pneumonia. Antimicrobial Agents and Chemotherapy 22, 406-8.

Tally, F. P., Ho, J. L. \& Gorbach, S. L. (1983). Thienamycin in the treatment of mixed infections. Proceedings of the 13th International Congress of Chemotherapy (Spitzy, K. H. \& Karrer, K. Eds). Vienna, Part 14/30-33.

Witte, J. L., Sapico, F. L. \& Canawati, H. N. (1982). In vitro susceptibility of methicillinresistant and methicillin-susceptible Staphylococcus aureus strains to $N$-formimidoyl thienamycin. Antimicrobial Agents and Chemotherapy 22, 906-8.

Yu, V. L. (1981). Enterococcal superinfection and colonization after therapy with moxalactam, a new broad-spectrum antibiotic. Annals of Internal Medicine 94, 784-5. 